\title{
Development and implementation of an emission optimization model for passenger flight bookings
}

\author{
Andreas Schennings, Joel Larsson and Markus Robèrt ${ }^{*}$
}

\begin{abstract}
In this analysis we discover the potential of a more transparent emission declaration system, in order to a) facilitate for environmentally concerned consumers to choose low-emission flights, and b) provide data for a future emission trading system where the aviation industry is accounted for its emission costs. Some air travel consumers book flights through low-cost flight ticket price comparison websites, that offer comparisons on price, convenience, travel time, and other factors relevant to the consumer. As a basis for this study, an algorithm designed for "flight $\mathrm{CO}_{2}$ emissions comparisons", was developed and implemented on Sweden's largest flight ticket price comparison website that compares flights by $\mathrm{CO}_{2}$ emissions in $\mathrm{kg}$ per passenger and trip. A visitor to the site can now also select a flight based on the ranking of carbon emission levels from each flight. In addition to the implementation of the algorithm in a commercial aviation booking system, a survey was conducted to analyze consumer preference data to glean insights and make conclusions about flight ticket price sensitivity, convenience, environmental awareness and potential for behavioral change among air travel consumers.

The findings from this study indicate that the algorithm will not act as a catalyst for emission reductions in the aviation sector, unless it is complemented by emission reduction policies and/or introduction of a fair emission taxation system. Furthermore, the aviation sector should be obliged to report accurate emission data on all tickets in order to bring full transparency to consumers searching low emission transport modes.
\end{abstract}

Keywords: Sustainability, Transport, Planning, Aviation, Climate, Emission

\section{Introduction}

The world is becoming increasingly aware of man-made climate change and there are strong indications that the climate is changing to an extent that cannot be considered as natural [1]. Following the United Nations Climate Change Conference in Paris 2015, many nations are united in the belief that changes must be made and that emissions caused primarily by coal and oil must be reduced [2]. The aviation industry is one of the fastest growing sources of emissions. Worldwide air travel is a significant contributing factor to climate change, and there is significant risk that aviation emissions will increase during the coming years, which would counteract international efforts to keep global warming below $2{ }^{\circ} \mathrm{C}$ [3]. Passenger flights account for approximately $4-5 \%$ of

\footnotetext{
* Correspondence: mrobert@kth.se

Department of Sustainable Development, Environmental Sciences and Engineering, Royal Institute of Technology, Stockholm 100 44, Sweden
}

total man-made emissions $[4,5]$. These changes will affect humanity in the long run by way of rising sea levels, changes in precipitation levels, an increased risk of forest fires, landslides and drought $[6,7]$.

Global passenger traffic increased by $6.5 \%$ in 2015 compared with 2014 and over the same time period, capacity among global airlines increased by $5.6 \%$, meaning that the industry continues to invest unhindered in flight and passenger volumes [8]. Commercial passenger flights are by far the most emissions-intensive mode of transport despite being relatively cheap when compared with other modes of transport [9]. This is because the global airline industry is exempted from bearing the cost of the emissions it produces [10]. Various tax exemptions significantly undermine the effect of climate compensations [11], and the level of taxation varies significantly between countries [12]. In Sweden, the global airline industry does not pay value added tax on

(C) The Author(s). 2019 Open Access This article is distributed under the terms of the Creative Commons Attribution 4.0 International License (http://creativecommons.org/licenses/by/4.0/), which permits unrestricted use, distribution, and 
international flights and only 6\% value added tax on domestic flights in Sweden. Compared with driving a car, airlines pay just $1 / 10$ th of their cost in emissions, i.e., they do not pay any tax on aviation fuel [13, 14]. Furthermore, a wide range of other subsidies are also used, including grants (research and development, exports, investments, loss coverage), equity infusions, loans and loan guarantees, public service obligations, hidden subsidies (reduced infrastructure fees, cross-subsidization, monopoly rights) [15].

According to the United Nations climate change goals to limit global temperature rise to well below $2{ }^{\circ} \mathrm{C}$, carbon emissions will have to fall by between 41 and $72 \%$ by 2050 , compared to 2010 [6]. As a consequence, the commercial aviation industry has set own climate targets: improving fuel efficiency by an average of $1.5 \%$ per year from 2009 to 2020, stabilizing emissions from 2020 with carbon-neutral growth and an aspirational goal to reduce net emissions from aviation by $50 \%$ by 2050 compared to 2005 levels [16].

In order to make the airline industry part of a sustainable transport system in the future, it must a) decrease flight volumes, b) introduce renewable fuels, and c) make future aircrafts more emission-efficient. It is possible that a future widespread use of an online tool, such as the one developed in this study, might fill a role for air travel consumers in order to enable them to compare flights according to various factors affecting flight emissions. Thus, an algorithm making flight emissions more transparent to the consumers might hypothetically work as a catalyst, driving the development of lowering emissions in the airline industry.

The algorithm developed in this study designates a flight an environmental classification based on its impact on the environment, i.e., a value that enables the flight to be ranked. In turn, this classification is based on a number of relevant parameters for the flight. The problem is therefore reduced to locating and researching all of the parameters that can have an impact on the emissions from a flight and how they interact. These parameters build an equation that calculates flight emissions. This equation is the essence of the algorithm; while it is the algorithm that decides in which case and in which way the equation should be used. In the study the algorithm is designed for ranking carbon emissions (equivalents) from flights. From both a consumer perspective, as well as from a sustainable transport perspective, the algorithm could be expanded and integrated into a comprehensive classification of other transport modes, for example; trains, buses, boats and cars.

The following main research questions have been addressed in the study:
- How can an algorithm that classifies/ranks flights be developed and implemented, based on parameters affecting emissions?

- How can consumers be persuaded to use it for the purpose of booking a flight that releases the least amount of emissions into the atmosphere?

- What purpose might the algorithm fill as a catalyst in the transition towards a sustainable transport sector?

- What is needed as regards data provision and future economic taxation systems in order for the algorithm to reach its full potential?

The following issues have been selected to break down this question and operationalize it:

- Which parameters affect emissions from an aircraft?

- How can the parameters be combined into an equation that calculates the $\mathrm{CO}_{2}$ emissions from an aircraft?

- Which flights release the least emissions, according to how the algorithm ranks them and why?

- What motivates air travel consumers to select a flight that contributes the least possible emissions?

- What restrictions on data provision are present in order to increase precision of the algorithm?

- Could the algorithm play a key-role as a complement with a taxation system that makes emission rankings more directly correlated with consumer costs?

\section{Method}

The two-fold nature of this study required the running of two processes in parallel; one process produced the equation and the development of the algorithm for calculating and ranking the emissions from passenger aircraft, while the other process explore factors that might motivate air travel consumers to select a flight with the least impact on the environment.

\section{The development of the algorithm}

The flight emissions have been calculated according to the equation below Eq. (1), with the input parameters detailed in Table 1.

The equation is built upon those parameters that have been assessed as having the greatest impact on flights, and those where there is a realistic chance of obtaining data. During the algorithm creation process various relevant parameters were identified, but not all of them were made available for reasons of business confidentiality, such as passenger volume per route. Parameters that would optimize the equation are to be found in the Discussion section exploring suggestions for improvements. 
Table 1 Parameters used for calculating emissions from flight bookings

\begin{tabular}{|c|c|c|}
\hline Parameter & Description & Unit \\
\hline U & Emission measured in $\mathrm{CO}_{2}$ & $\mathrm{~kg}$ \\
\hline C & $\mathrm{CO}_{2}$ conversion factor: $3.15 \mathrm{~kg} \mathrm{CO}$ equals $1 \mathrm{~kg}$ aviation fuel (JET A1). & $\mathrm{kg} / \mathrm{kg}$ \\
\hline LTO & Fuel consumption for landing, takeoff and taxi, measured in kg aviation fuel (JET A1) & $\mathrm{kg}$ \\
\hline CCD & Fuel consumption for climb, cruise and descent measured in kg aviation fuel (JET A1) per km travel. & $\mathrm{kg} / \mathrm{km}$ \\
\hline D & Distance & $\mathrm{km}$ \\
\hline S & Sharklet/Winglet-variabel: 0.95/1 L aviation fuel per liter aviation fuel. & $\mathrm{L} / \mathrm{L}$ \\
\hline $\mathrm{F}$ & High altitude factor: $1.9 \mathrm{~kg} \mathrm{CO} 2$ per $1 \mathrm{~kg} \mathrm{CO}$ & $\mathrm{kg} / \mathrm{kg}$ \\
\hline P & Seating configuration (total seats). & - \\
\hline B & Passenger cabin factor (percentage sold seats). & - \\
\hline
\end{tabular}

$$
U=C * \frac{L T O+C C D * D * S * F}{P * B}
$$

In brief, the distance (D) is multiplied by the amount of aviation fuel per unit of distance (CCD) and the adjustment factor ( $\mathrm{S}$ and $\mathrm{F}$ ) for sharklet- and high altitude factor, plus the amount of aviation fuel used for take-off, landing and ground time (LTO). The sum is then divided by the average number of passengers occupancy rate $(\mathrm{B})$, multiplied by the number of seats $(\mathrm{P})$. Finally, everything is converted into $\mathrm{CO}_{2}$ equivalents $(\mathrm{C})$ in Eq. (1) is carbon dioxide conversion factor representing that burning of $1 \mathrm{~kg}$ aviation fuel (JET A1) produces $3.15 \mathrm{~kg}$ of $\mathrm{CO}_{2}$ emissions, according to Penner [17]. The parameters in the above equation will be discussed in the subsequent subsections.

Civil aircraft manufacturer Airbus has made a compilation of how a flight can be divided into approximate and different phases in which the phases have various major impact on fuel consumption [18]. The algorithm utilizes these different phases to describe fuel consumption as realistically as possible. The various phases of a flight are taxi, takeoff, climb, cruise, descent and landing [18]. Taxiing involves the relatively short movements on the ground an aircraft makes at an airport between the gate or parking area and the runway.

\section{Fuel consumption (LTO and CCD)}

The Emission Inventory Guidebook, issued by the European Environment Agency (EEA), contains a table of the extent of emissions from the most common types of aircraft on scheduled routes [19]. The data suggest that the different models of aircrafts burn various amount of aviation fuel per flown kilometer, depending on phase.

Data from EEA (Table 2) is divided into two values; Landing, Take Off, Taxi (LTO) and Climb, Cruise, Descent (CCD). LTO describes how much aviation fuel (in $\mathrm{kg}$ ) is consumed in the landing, takeoff and taxiing phases. The CCD value describes (in $\mathrm{kg}$ ) the aviation fuel consumed in the climb, cruise and descent phases over distance.

In this study, the value of CCD is linearized by using the least squares method on fuel consumption data, for aviation trips between different destinations. The $R^{2}$ value varies between different aircraft models between 0.998 and 1 and this means that linearization provides a good approximation.

However, there are two aircraft models on which there are no data available from EEA that are quite frequently used. To achieve as accurate approximation as possible, these models have been added by comparing parameters on similar models by the manufacturer. These parameters are LTO and CCD.

In those cases where the aircraft model is missing from the input data, four different and calculated models are used, depending on distance. The model is known as ZX, with a suffix representing the distance, as can be seen in Table 3 below.

The ZX model has been produced by combining data from web site flightradar24, as well as data compiled by seating configuration and emissions data from EEA. The data from flightradar24 contain the aircraft types mentioned earlier, in addition to the 15 most common aircraft types per distance (above) and grouped together with emissions data and seating configurations. The number of flights per aircraft model has been weighed against each other and a standard model for the distance has been created. In this study it is known as the ZX model.

\section{Winglets(s)}

Modern aircraft have winglets (sharklets), as they are known, on their wingtips. These reduce the wingtips vortices which would otherwise occur. The device reduces fuel consumption by around 5\% during flights [20]. Aircraft equipped with such devices are apportioned a reduction of the total emissions value, corresponding to $5 \%$, by the algorithm. This number is not calculated in the CCD because the EEA data do not 
Table 2 Example of available emission data from EEA, showing emissions per kilometer during two different phases for various aircrafts

\begin{tabular}{|c|c|c|c|c|c|}
\hline & $125 \mathrm{~km}$ & $250 \mathrm{~km}$ & $500 \mathrm{~km}$ & $750 \mathrm{~km}$ & $1000 \mathrm{~km}$ \\
\hline Row Labels & Sum of BurntFuel_kg & Sum of BurntFuel_kg & Sum of BurntFuel_kg & Sum of BurntFuel_kg & Sum of BurntFuel_kg \\
\hline A306 & 3824 & 5334 & 8052 & 10,922 & 13,752 \\
\hline Climb/cruise/descent & 2101 & 3610 & 6329 & 9199 & 12,029 \\
\hline LTO & 1723 & 1723 & 1723 & 1723 & 1723 \\
\hline A310 & 3412 & 4799 & 6759 & 8993 & 11,205 \\
\hline Climb/cruise/descent & 1905 & 3293 & 5252 & 7487 & 9698 \\
\hline LTO & 1506 & 1506 & 1506 & 1506 & 1506 \\
\hline A318 & 1683 & 2417 & 3466 & 4582 & 5717 \\
\hline Climb/cruise/descent & 998 & 1732 & 2781 & 3897 & 5032 \\
\hline LTO & 684 & 684 & 684 & 684 & 684 \\
\hline A319 & 1763 & 2501 & 3508 & 4594 & 5702 \\
\hline Climb/cruise/descent & 1074 & 1812 & 2819 & 3905 & 5013 \\
\hline LTO & 688 & 688 & 688 & 688 & 688 \\
\hline A320 & 1935 & 2704 & 3822 & 5073 & 6312 \\
\hline Climb/cruise/descent & 1062 & 1831 & 2949 & 4200 & 5439 \\
\hline LTO & 873 & 873 & 873 & 873 & 873 \\
\hline A321 & 2313 & 3231 & 4723 & 6338 & 7930 \\
\hline Climb/cruise/descent & 1279 & 2196 & 3689 & 5303 & 6896 \\
\hline LTO & 1034 & 1034 & 1034 & 1034 & 1034 \\
\hline
\end{tabular}

include these newer aircraft models. In the algorithm the parameter is known as $\mathrm{S}$ and is 0.95 on the models equipped with winglets and 1 for aircraft not equipped with winglets.

\section{Altitude coefficient ( $F)$}

Emissions from aircraft are those products created upon the burning of aviation fuel and harmful to the environment. In addition to $\mathrm{CO}_{2}, \mathrm{NO}_{\mathrm{x}}$ and $\mathrm{SO}_{\mathrm{x}}$ we can also include Air Induced Cloudiness (AIC) - the amount of cirrus clouds caused by emissions of $\mathrm{H}_{2} \mathrm{O}$, Black Carbon (BC) and soot particulates [21]. Background cloud created by aircraft contrails causes both global warming and cooling effects because the clouds reflect infrared radiation towards earth. However, the combined warming and cooling effects mean that the emissions of condensation at high altitude are contributing to the greenhouse effect. For the purposes of this report this

Table 3 When data is missing from EEA, approximations are done according to assumptions on travel distances for regional, short-haul, medium-haul, and long-haul distances

\begin{tabular}{llll}
\hline Model & Type of travel & Minimum distance, $\mathrm{km}$ & Maximum distance, $\mathrm{km}$ \\
\hline ZXR & Regional & - & 1900 \\
ZXS & Short-haul & 1900 & 5600 \\
ZXM & Medium-haul & 5600 & 11,000 \\
ZXL & Long-haul & 11,000 & - \\
\hline
\end{tabular}

factor is known as 'altitude coefficient', F, and describes how much higher the impact of emissions of primarily AIC has at high altitude, compared to ground level emissions. The $\mathrm{F}$ value varies depending on altitude, the location on earth of the emissions, as well as time of day and at which temperature. According to the best and current scientific knowledge this $\mathrm{CO}_{2}$ factor lies between 1.9 (low) and 2.0 (high) times total amount of $\mathrm{CO}_{2}$ emissions based on GWP100 (Global Warming Potential over $100 \mathrm{yr}$ ). Lee et al. [21] also state that $\mathrm{CO}_{2}$ and $\mathrm{H}_{2} \mathrm{O}$ (AIC) are the "most relevant" emissions. The other emissions; $\mathrm{NO}_{\mathrm{X}}$, and $\mathrm{SO}_{\mathrm{x}}$, arise in such small quantities in proportion to $\mathrm{CO}_{2}$ as to be negligible and this is reflected in the equation. The 1.9 (low) value has been used in the algorithm as $\mathrm{F}$ and this value is multiplied by CCD but not LTO because its relevance pertains only to high altitude.

\section{Distance (D)}

Distance, $D_{\text {Direct }}$ is the distance between two locations, measured in $\mathrm{km}$ calculated by using Vincenty's formula [22]. Information on the exact distance that an aircraft flies between two airports is not exact. Even if the route is a relatively straight one from the outbound airport to the inbound airport, external factors such as weather conditions and conflicts may mean that an aircraft has to be re-routed. Aircraft generally fly a longer distance than the straightest route, often shown as the 'scheduled 
route'. In some cases, aircraft must queue up to land, circling an airport until being given the go ahead for landing, this is known as a 'holding pattern' and airports use it to control capacity [23].

However, to compensate for the distance being longer, data from the flightradar24 web site have been analyzed. Flightradar24 is a global flight tracking service that provides real-time information about thousands of aircrafts around the world. Flightradar24 provides information on time, position, aircraft model, aircraft registration number, as well as the outbound and inbound airports. In total 22.6 million items have been stored and analyzed.

Flights that took off or land outside a 24-h interval, as well as items which gave rise to analytical errors, such as technical stops, were excluded. This left us with details on the exact distance of 28,659 flights. These were then curve-fitted to a linear curve in part by using the least squares method (Fig. 1) with $\mathrm{R}^{2}=0.99647$. The distance equation is $\mathrm{D}=1.0347 * \mathrm{D}_{\text {Direct }}+67.166 \mathrm{~km}$.

\section{Seating configuration $(P)$}

$\mathrm{P}$ is the number of people that can be seated on an aircraft and it is configured by the airliner who chooses how to configure the fuselage. Generally, an economy seat takes up less space than a business class or firstclass seat.

Where there is no available data on seating configuration for a specific model for a specific airline, the average for that model across all of the airlines is used. A sample of the aircraft manufacturers' numbers against the average shows the differences that exist (Table 4).

\section{Passenger seat occupancy (B)}

The parameter $\mathrm{B}$ describes the ratio of passengers to passenger seats on an aircraft where 1 would be $100 \%$. The algorithm currently uses the passenger seat occupancy rate per airline because this information is public and can usually be found in the annual accounts of the airlines. If there is no information available on an airline the average value for all flights around the world is used. This is provided in the website of International Air Transport Association [24].

\section{Analyzing consumer preferences}

A questionnaire containing 14 questions was disseminated by email to some 50,000 Swedish subscribers to Flygresor's (online) newsletter in order to address the issues of motivation, and to explore consumers' willingness to pay for reduced emissions in relation to travel comfort. The questionnaire period was from April 12, 2016 to April 22, 2016. The main questions in the questionnaire focused on the respondents' level of interest in the environment and their willingness to compromise on price and comfort for the sake of the environment. We used number of reduced centimeters in legroom, as an indicator for comfort, since it also relates to a potential increase of the occupancy rate of the aircraft (which directly relates to reduced $\mathrm{CO}_{2}$-emssions). The answers were analyzed with the help of pie charts and tables, attached as appendices, as well as T-tests and regression analyses with variables deemed significant to the T-test.

Out of some 50,000 subscribers, 1650 respondents returned fulfilled questionnaires. Out of the 1650 respondents (824 men and 820 women), the respondents

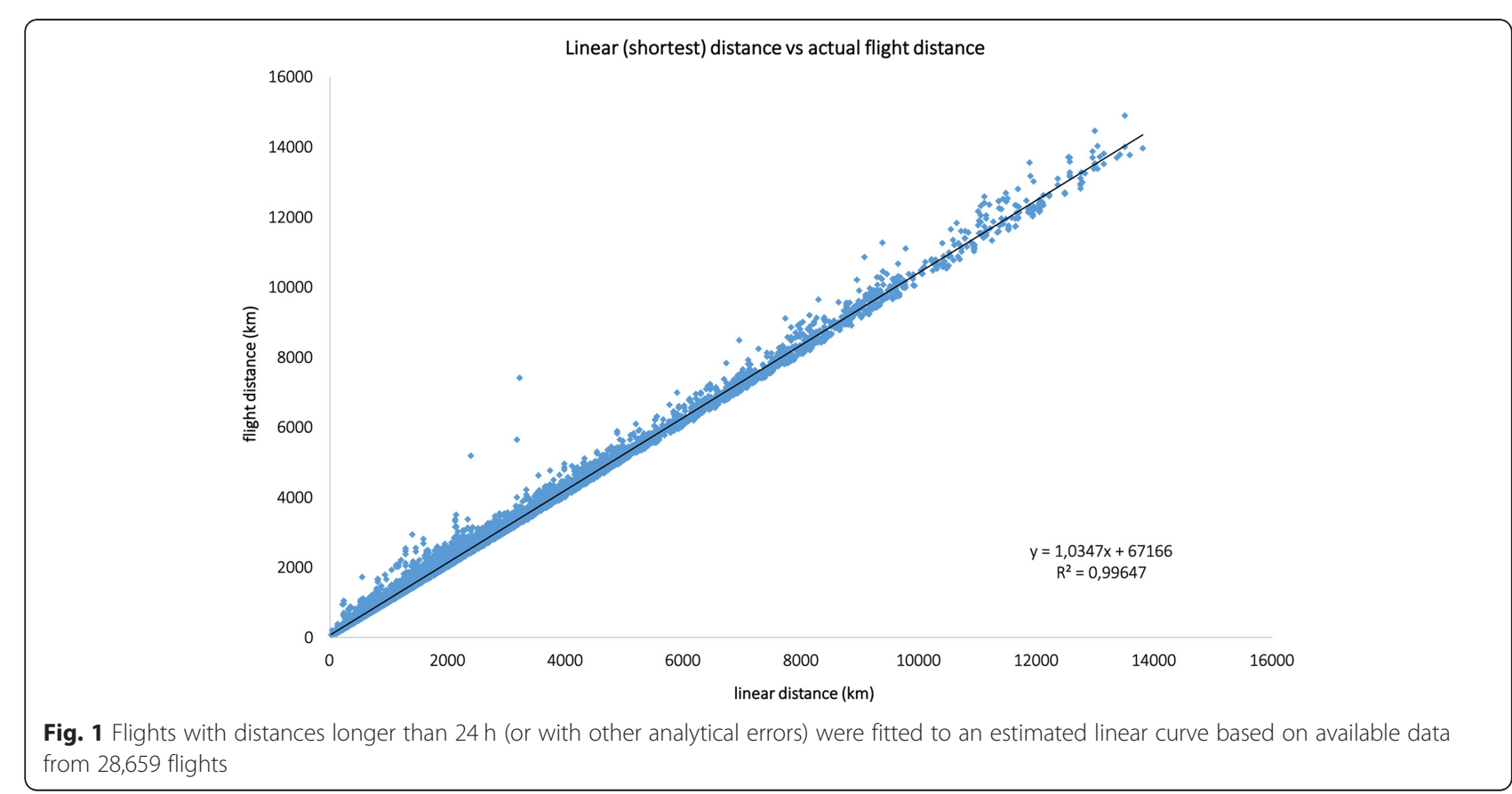


Table 4 Where there is no available data on seating configuration for a specific aircraft, the average for that model across all of the airlines is used

\begin{tabular}{lll}
\hline Aircraft model & Manufacturer's specification & $\begin{array}{l}\text { Computed } \\
\text { average }\end{array}$ \\
\hline Airbus 380-800 & 525 & 517 \\
Boeing 737-800 & only economy/two classes 189/162 & 166 \\
Airbus A320-200 & only economy/two classes 164/150 & 158 \\
\hline
\end{tabular}

age distribution was as follows: 27 respondents were between 0 and 19 years, 87 respondents were between 20 and 25 years, 201 respondents were between 26 and 39 years, 750 respondents were between 40 and 59 years and 586 respondents were over 60 years old. There are certainly reasons to suspect that the respondents are not representative as a "population mean" when it comes to environmental concern, i.e., it is likely that they have a greater interest in matters of the environment than the average flight passenger. However, as becomes clear in the results section to follow, the findings from the survey point towards a central conclusion that even if environmental awareness among these respondents is higher than the average, cost and comfort are the most critical factors when selecting a flight. Thus, conclusions could be drawn from this survey, even though it might suffer from selection bias.

\section{Results}

\section{The algorithm generates intuitive results}

The algorithm has been test run on a database of various parameters before being implemented on the Flygresor.se website. The results showed, as expected, that those airlines that fill their aircraft to full capacity release less emissions per passenger. Simply put, this is because passengers on a flight are only a very small part of the weight of the aircraft. For example; if the passenger number on an Airbus 380 is increased from 500 to 550 passengers, an increase of $10 \%$, the extra passengers account for just $5000 \mathrm{~kg}$ of extra weight out of a total maximum weight of $560,000 \mathrm{~kg}$; or not even $1 \%$ of the maximum weight [25].

The results also show that the same flights often appear at the top of the rankings when ranked on price or emissions. The correlation between these two ranking parameters is explained from the fact that budget airlines often fill their aircrafts to full capacity to optimize revenue. The seat occupancy rate of one budget airline is between 84 and 93\%, 2015 according the annual reports that were analyzed [26] while other airlines stood at around 76 to $83 \%$.

Other variables that positively affect the ranking include; winglets, direct flights (no stopovers), and aircraft engine/fuel efficiency.
Consumer preferences revealed from the web survey The results from the web survey disseminated to Flygresor.se customers showed that $1.6 \%$ of respondents stated the environmental impact as the most important factor when booking their latest flight, whereas $81.8 \%$ of respondents stated that price was most decisive as shown in Fig. 2 (comfort was given next highest priority of $16.6 \%$ of the respondents).

\section{How could respondents be persuaded to select a flight that contributes to lower emissions?}

'The option which is the best for the environment should be easy to choose and come at a reasonable price to win support. I choose the environmentally friendly option if I can afford it.'

The quote above was received in answer to an open question in the survey. It illustrates what many respondents expressed in their comments; that, to some degree, the environment is a consideration, but price is the decisive factor. That the environment is in last place (Fig. 2 pie chart) can likely be explained by the fact that flying, by its very nature, is not environmentally friendly. Therefore, it cannot be expected that flight passengers make selections primarily based on environmental considerations.

Some of the respondents however, could consider paying more in exchange for less environmental impact. A T-test, coupled with a regression analysis, showed with a $1 \%$ significance level, that those willing to pay SEK 5001000 more for a flight with less emissions were also those that:

- Purchased ecological goods

- Would like to be reminded/alerted to choose a more environmentally friendly flight

- Thought comfort was the single most important factor on their last trip

For those respondents with strong purchasing power, who prioritized comfort, and to some extent, took the environment into consideration, there existed a willingness to reduce emissions by paying a premium and they were willing to be reminded of it. On a comparable trip (according to travel time and comfort), 70\% would have selected a trip that contributed to lower emissions if they had received a reminder/alert.

The figures from airline websites show that flights that have less space between the seats contain more passengers than average [25]. The flights of companies that use this practice are often the cheapest and emit less emissions per person, based on flights with no stopovers. At least as regards flying, it is not apparent that it costs 


\section{What was most important to me when choosing the last flight I booked?}

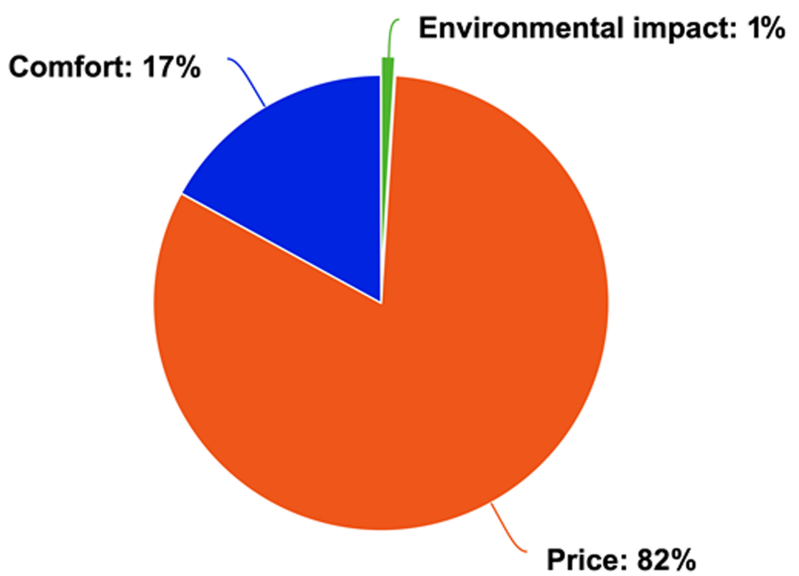

Fig. $\mathbf{2}$ It is evident that the respondents are most sensitive to price when choosing flights. Only $1 \%$ of the respondents state that environmental concern is the most decisive factor

more to save the environment, indeed the reverse is true, the lower the price the less harmful effects on the environment since thees flights carry more passengers. This does raise the question; which of the respondents would be willing to give up legroom?

There does seem to be a correlation between respondents who are environmentally aware and legroom. A Ttest with a $1 \%$ significance showed that respondents who thought that it was worth giving up $3-5 \mathrm{~cm}$ legroom on a return flight ticket from Sweden to the UK with a premium carrier and $1-10 \%$ less $\mathrm{CO}_{2}$ emissions are:

- Sort their household waste more

- Purchase ecological goods

- State that the most important factor for their last trip was the climate

- Travel more on public transport/by foot based on the last week

- Would like to be reminded/alerted to choose a more environmentally friendly flight

\section{Household waste sorting versus willingness to give up legroom} The willingness of those who sort household waste to give up legroom is shown in Table 5. It is evident that respondents who replied that they sort household waste have a higher frequency of claiming that they would consider giving up legroom, in comparison to respondents that do not sort household waste (figures in parentheses). Note that the difference is more than twice as large for $5 \mathrm{~cm}$ decreased legroom and 25\% less emissions.

Furthermore, we notice that respondents seem to be more willing to compromise on legroom if the environmental impact is greater. However, somewhat expected, respondents seem to be more willing to compromise on legroom on shorter flights than longer flights. In this case respondents have a greater tendency to choose to make this compromise in return for 10 or $25 \%$ less emissions (Table 5).

When conducting a T-test, we find that respondents who thought that it was worth giving up 3-5 cm less legroom on a return flight ticket from Sweden to the UK with a premium carrier and $1-10 \%$ less $\mathrm{CO}_{2}$ emissions are respondents that (significance level $1 \%$ ):

- Answer that the most important factor on their last flight was comfort

- Are younger

- Are female

- Purchase more ecological goods

- Want a reminder/alert

Table 5 Proportion of respondents (\%) stating they are willing to give up legroom, if reductions of $\mathrm{CO}_{2}$-emissions were obtained. Bold figures display respondents sorting household waste, and figures in parentheses display consumers that do not sort household waste

\begin{tabular}{llll}
\hline & $1 \%$ decreased $\mathrm{CO}_{2}$ & $10 \%$ decreased $\mathrm{CO}_{2}$ & $25 \%$ decreased $\mathrm{CO}_{2}$ \\
\hline Will not compromise on legroom & $61.1(80.2)$ & $32.2(66.7)$ & $25.5(62.5)$ \\
$3 \mathrm{~cm}$ decreased legroom & $14.0(6.3)$ & $31.4(17.7)$ & $23.6(17.7)$ \\
$5 \mathrm{~cm}$ decreased legroom & $24.9(13.5)$ & $36.4(15.6)$ & $50.9(19.8)$ \\
\hline
\end{tabular}


- Sort household waste more

- Travel more on public transport/by foot in the last week

- Flew less frequently in the last year (in Sweden)

- Flew less frequently in the last year (outside Europe)

\section{User data from the booking system reveals minor consumer} interest in climate ranking

At least in a small fraction of the respondents (primarily the most environmentally concerned customers) some positive correlations are evident between willingness to pay extra, or give up legroom in order to reduce emissions. However, the survey data strongly support the conclusion that among the mass of aviation customers, the emission sorting algorithm would not contribute significantly to reducing flight emissions, just from launching it in the present booking systems. Revealed preference data from Flygresor.se's booking system supports these findings from the web-survey even more. During the first 18 months when the system has been available on the booking system, revealed preference of on average $1.4 \%$ of the customers have clicked on the climate ranking function. In comparison, revealed preference of in average $31.9 \%$ of the customers clicked on the "best sorting function", that optimizes time and price of each flight (Table 6).

We conclude that the stated preference data (based on the survey) and the revealed preference data (based on clicks from the booking system) are quite coherent. As presented in Fig. 2, 1.6\% of the respondents that stated the environmental impact as the most important factor when booking their latest flight, and $16.6 \%$ of the respondents stated that comfort is the most important factor.

\section{Discussion}

What environmental and systemic changes, leading to reduced $\mathrm{CO}_{2}$ emissions into the atmosphere, would be needed if the algorithm were to be a breakthrough? It is unclear whether any systematic impact on the environment can be expected, from just implementing the

Table 6 Revealed preference data showing proportion of customers (\%) on Flygresor.se, sorting trips based on $\mathrm{CO}_{2}$, or based on time and price

\begin{tabular}{lll}
\hline Time & $\mathrm{CO}_{2}$-sorting & Time/price-sorting \\
\hline Q1 2017 & 1.6 & 30.8 \\
Q2 2017 & 1.2 & 27.4 \\
Q3 2017 & 1.1 & 29.4 \\
Q42017 & 1.4 & 34.2 \\
Jan 2018 & 1.5 & 37.7 \\
Average & 1.4 & 31.9
\end{tabular}

Source: Google Analytics Flygresor.se algorithm as an option in the flight booking system. It is clear that there would have to be substantially higher emission concerns among flight consumers, in order for the algorithm to give impact on a systems level in the present absence of a fair taxation system. From an optimistic viewpoint, the survey results displayed in this study show a slight awareness of the environment among some consumers, and this might contribute to, at least a limited use of this emission ranking tool.

A number of respondents were of the opinion that a higher flight ticket price equates to a greener trip and a number of respondents would be willing to pay for it. It was confirmed by the T-test that respondents who would be inclined to pay between SEK 500 and 1000 more for a more environmentally friendly flight are also those who prioritized 'comfort' as the most important parameter. These respondents did, to some extent, consider the environment and are, from what could be interpreted from the survey, the people with purchasing power. This result is in line with Montreal citizens that were willing to pay a small amount in exchange of receiving environmental information about their travel decisions, in order to change their travel behavior [27].

Another (indirectly) positive result was the evident price sensitivity among the customers. Since $81.8 \%$ of the respondents were most concerned with finding low price tickets, the algorithm sorting of low emission flights, quite often correlate with low price flights. This is currently the best choice for the environment on the basis that the cheapest flight ticket is with a budget airline with the highest occupancy rate/seating configuration and with the fewest stopovers. Budget airlines generally create lower emissions, according to the algorithm.

However, the usage of the algorithm has increased just to a limited extent since implementation. In January $2018,1.54 \%$ of the visitors on flygresor.se clicked "emission sorting". But compared to time- and price sorting, generating clicks from $37.67 \%$ of the visitors, the revealed preference is clear: price and travel time are more decisive factors than the environment. Therefore, an impact from a systems perspective seems unrealistic at present pricing conditions. However, if the algorithm were to be implemented as a means to assess emissions into monetary terms in a future taxation system, it is likely that consumers would book tickets according to e.g. high-density seating configurations, higher occupancy rates, emission efficient types of airplanes, etc.

As a consequence, in a hypothetical situation where a fair taxation system was implemented (where the aviation industry would cover its emission costs) the algorithm would have the potential to accelerate the aviation industry towards lowering emissions. Actors in the aviation industry would gain business advantages over its 
competitors as they would be compelled to offer more emission efficient (and cheaper) aviation alternatives. In the present taxation system, implementing the emission ranking algorithm is mainly motivated by a potential of achieving a 'greener profile', which of course is of marginalized value from an emission perspective.

Furthermore, there are potential environmental risks associated with the algorithm. Other modes of transport, such as train, are substantially more environmentally friendly. The environmental impact of a flight is between 3 and 1300 times more harmful to the environment than the corresponding journey by train in Europe and in Sweden [28, 29]. There is a risk that if implementing an emission sorting algorithm in the aviation booking system solely, people are fooled into believing that flying could be an environmentally friendly alternative just because there are a variety of emission impacts from different flights. A potential scenario is that some consumers may use the algorithm to suppress their bad consciences and fly more. In this way the algorithm would become a type of "greenwash tool", without inducing long-term change in travel behavior.

Simply put, there has to be dramatic reduction in the $4-5 \%$ of emissions that the airlines are responsible for, in order to achieve climate change goals $[2,13]$. Without tangible economic consequences and incentives, consumer behavior is unlikely to change. Recently the price of a flight ticket and the price of a train ticket, based on a trip in Sweden, are around the same level [9].

A major reason that flying is "cheap" is that the airlines pay very little towards their emissions of greenhouse gases, due to a wide range of subsidies. For example, a motorist pays more than 10 times as much for the emissions from their car $[13,15]$. A policy instrument such as a carbon dioxide tax covering airline would need to be introduced, but this requires international agreement which could be delayed until after 2020. In the meantime, Sweden could go the way of the UK and offset emissions by levying a tax on flight tickets [13]. According to the principles of scarcity and loss aversion the effect of a price hike would be major, and many consumers would choose a cheaper, and in the best case, a more environmentally friendly alternative $[18,30]$. The climate compensated revenue could be used for investment in public transport. And finally, a more climate neutral aviation fuel, for example biofuel, would make an even bigger difference. These measures are at discussion stage, but they still represent possible interim targets towards achieving the climate goals [31].

But what if the algorithm was implemented as an imperative managing tool at an organizational level, as a way to curb travel emissions towards defined climate targets? There are at present a great number of companies, municipalities and other organizations in Sweden, that have defined rigorous target scenarios and action plans in order to meet future global climate targets (see implementation of the CERO model [32-35]). For further research, we intend to analyze the impact from implementing the algorithm in one of these organizations as a mandatory tool for employee travel bookings. The impact might be even more substantial if the implementation is complemented with increased climate taxations and/or emission compensations posed on flight tickets.

Pending all or some of the above, air travel consumers and/or companies/organizations should be provided with economic incentives to select flights that have less impact on the environment and the algorithm developed in this study would potentially facilitate this. The results in this study indicate that in order for market forces to push down $\mathrm{CO}_{2}$-emissions in the aviation industry, to an extent needed for future climate targets, aviation must be subject to increased emission costs in a fair climate taxation system with other travel alternatives. The algorithm will not fill a role as a catalyst for the energy transition in the transport sector, unless the aviation industry fully covers all adherent emission costs.

\section{Conclusions}

The purpose of this study was to investigate the conditions and feasibility of developing an algorithm that calculates $\mathrm{CO}_{2}$ and other emissions from flights, as well as to investigate if this algorithm can function as a tool to influence consumer behavior towards more emission efficient aviation. The algorithm was implemented initially on Swedish flight ticket price comparison website flygresor.se. Over the period July 2016-January 2017 on average 34,613 customers (out of 2,258,633 customers in total) used the tool to compare flights based on their internal emission ranking.

The results produced by running the algorithm showed that the airlines that optimized passenger numbers on their aircraft and the ones flying straight with no stopovers also emitted the least amount of emissions per passenger. In many cases, such flights were also the cheapest, which flies in the face of the not uncommonly held view among respondents to the survey that more expensive flights are better for the environment. Possibly, the more expensive flights are more comfortable, but generally they are more harmful to the environment.

One of the results of the survey was that the key factors when booking a flight were price and comfort. However, it was evident that a small fraction of consumers was willing to pay a premium for flights with less environmental impact, and those respondents are in general more environmentally concerned (indicated by environmentally friendly behavior from waste management and ecological purchase practices). To some extent, there exists a willingness to pay for reduced emissions among more environmentally aware 
air travelers. However, the study also shows that price and comfort are the key factors when selecting a flight even among this group. The algorithm may have a role to play in increasing consumer environmental awareness by being the 'environmental choice' among other available parameters (price, convenience etc.) on flight ticket price comparison websites. Currently, in the absence of new "polluters pay policies", the impact of the algorithm is limited to a minority of more environmentally aware consumers.

Four main conclusions could be drawn from this study:

1. The revealed preference data indicate that customer "clicks" on the emission sorting function corresponds to just $1.4 \%$ of total customer traffic. This reveals that, at least in the present absence of an emission taxation system for the aviation sector, the algorithm has just a marginal impact on consumer behavior.

2. Stated preference data from the survey show that customers tend to prioritize price, travel time and comfort, over lowering emissions when ordering tickets.

3. The algorithm will not act as a catalyst for a renewable energy transition unless introduction of a) a fair emission taxation system where the algorithm would help provide with more accurate pricing of emission costs (which would likely have a substantial impact due to the price sensitivity revealed in this study), or b) as part of an organizations emission reduction program, where the algorithm could serve a role as a mandatory tool for employee flight bookings according to defined climate targets in the organization.

4. The aviation sector should be obliged to report more accurate and transparent emission data on all tickets in order to bring full information to consumers searching low emission transport modes. This concerns not only the aviation sector, but all actors in the transport system providing alternative travel modes.

\section{Authors' contributions}

All authors read and approved the final manuscript.

\section{Competing interests}

Andreas Schennings and Joel Larsson plan to commersialize the algorithm described in this paper, selling flight $\mathrm{CO}_{2}$ calculations to whomever are interested.

Received: 25 September 2018 Accepted: 2 August 2019

Published online: 07 October 2019

\section{References}

1. SMHI. Climate Change Causes by Man. Norrköping: Swedish Meteorological and Hydrological Institute; 2015 [in Swedish].

2. UN. Adoption of the Paris Agreement. Paris: United Nations; 2015.

3. T\&E. Grounded: How ICAO Failed to Tackle Aviation and Climate Change and What Should Happen Now. Brussels: Transport \& Environment; 2010.

4. T\&E. Global Deal or no Deal? Your free guide to ICAO's 38th triennial assembly. Brussels: Transport \& Environment; 2013.
5. SSNC. Five questions about air travel. Stockholm: Swedish Society for Nature Conservation; 2016. http://www.naturskyddsforeningen.se/sveriges-natur/2 013-5/fem-fragor-om-flygresor [in Swedish].

6. IPCC. Climate Change 2014: Synthesis Report. Geneva: Intergovernmental Panel on Climate Change; 2015.

7. MEE. Sweden's Sixth National Communication on Climate Change. Stockholm: Ministry of the Environment; 2014.

8. IATA. Demand for air travel in 2015 surges to strongest result in five years. Geneva: International Air Transport Association; 2016.

9. SSNC. So big polluter is the flight. Stockholm: Swedish Society for Nature Conservation; 2016. https://www.naturskyddsforeningen.se/flyginfo [in Swedish].

10. Strand J. Fuel charges in international aviation and shipping: how high; how; and why? Washington, DC: World Bank Blogs; 2013.

11. Pegels A. Taxing carbon in developing countries. Bonn: German Development Institute; 2018.

12. AT. Mapping out airport taxes around the world. London: Airport Technology; 2016.

13. Åkerman J. Transport systems meeting long-term climate targets: a backcasting approach [Ph.D. dissertation]. Stockholm: Royal Institute of Technology; 2011.

14. SP. Law on energy taxes. Stockholm: Swedish Parliament; 1994. https://www. riksdagen.se/sv/dokument-lagar/dokument/svensk-forfattningssamling/lag-1 9941776-om-skatt-pa-energi_sfs-1994-1776 [in Swedish].

15. Gössling S, Fichert F, Forsyth P. Subsidies in aviation. Sustainability-Basel. 2017;9:1295

16. ATAG. Aviation: benefits beyond Borders. Geneva: Air Transport Action Group; 2016

17. Vedantham A. Aviation and the Global Atmosphere: A Special Report of IPCC Working Groups I and III. Philadelphia: ScholarlyCommons; 1999.

18. Airbus. Commercial Aviation Accidents 1958-2014. Blagnac: Airbus; 2015.

19. EEA. EMEP/EEA air pollutant emission inventory guidebook, vol. 2013. Copenhagen: European Environment Agency; 2013.

20. Bargsten CJ, Gibson MT. Innovation in aeronautics: select technologies that have shaped modern aviation. Washington, DC: National Aeronautics and Space Administration; 2011.

21. Lee DS, Pitari G, Grewe V, Gierens K, Penner JE, Petzold A, et al. Transport impacts on atmosphere and climate: aviation. Atmos Environ. 2010:44:4678734.

22. Vincenty T. Direct and inverse solutions of geodesics on the ellipsoid with application of nested equations. Surv Rev. 1975;23:88-93.

23. IVAO. Holding Procedures. Geraardsbergen: International Virtual Aviation Organisation; 2015.

24. IATA. Passenger demand maintains historic growth rates in 2013. Geneva: International Air Transport Association; 2014

25. Airbus. A380 - Innovation. Blagnac: Airbus; 2016.

26. Ryanair. Annual Report. Swords; 2015. https://investor.ryanair.com/wp-content/ uploads/2015/07/Annual-Report-2015.pdf

27. Daher N, Yasmin F, Wang MR, Moradi E, Rouhani O. Perceptions, preferences, and behavior regarding energy and environmental costs: the case of Montreal transport users. Sustainability-Basel. 2018;10:514.

28. Åkerman J. Climate Impact from Foreign Travel. Stockholm: Royal Institute of Technology; 2008. http://www.tillvaxtreflektera.se/Rapporter/klimat_ konsumtion_utrikes_resor.pdf [in Swedish].

29. SJ. Environmental calculation. Stockholm: Swedish Railways; 2016. http:// www.miljokalkyl.port.se/resultat.cfm [in Swedish].

30. Kahneman D. Thinking, fast and slow. New York: Farrar, Straus and Giroux; 2011.

31. T\&E. Radically cleaner air travel possible but governments need to act now - NGO. Brussels: Transport \& Environment; 2018.

32. Robèrt M. Mobility management and climate change policies [Ph.D. dissertation] Stockholm: Royal Institute of Technology; 2007.

33. Robèrt M. A model for climate target-oriented planning and monitoring of corporate travel. Int J Sustain Transp. 2009;3:1-17.

34. Robèrt M. Climate and economic research in organisations and from a macro perspective. Progr Ind Ecol. 2009;6:265-84.

35. Robèrt $M$. Engaging private actors in transport planning to achieve future emission targets - upscaling the climate and economic research in Organisations (CERO) process to regional perspectives. J Clean Prod. 2017; 140:324-32 


\section{Publisher's Note}

Springer Nature remains neutral with regard to jurisdictional claims in published maps and institutional affiliations.

- fast, convenient online submission

- thorough peer review by experienced researchers in your field

- rapid publication on acceptance

- support for research data, including large and complex data types

- gold Open Access which fosters wider collaboration and increased citations

- maximum visibility for your research: over $100 \mathrm{M}$ website views per year

At BMC, research is always in progress. 